\title{
The Accuracy Validation of FireFACE Software in Analyzing Facial Expressions of Urban Forest Visitors
}

\author{
Hongxu Wei ${ }^{1, *}$ and Ping Liu ${ }^{2}$ \\ 1 Key Laboratory of Wetland Ecology and Environment, Northeast Institute of Geography and \\ Agroecology, Chinse Academy of Sciences, Changchun 130102, China; weihongxu@iga.ac.cn (H.W.) \\ 2 College of Forestry, Shenyang Agricultural University, Shenyang 110866, China; lp 79@syau.edu.cn \\ (P.L.) \\ * Correspondence: weihongxu@iga.ac.cn
}

\begin{abstract}
The construction of sustainable urban forests follows the principle that well-being in people is promoted when exposed to tree population. Facial expression is the direct representation of inner emotion that can be used to assess real-time perception in urban forests. The emergence and change of facial expressions for forest visitors are in an implicit process. The reserved character of oriental races strengthens the requirement for the accuracy to recognize expressions through instrument rating. In this study, a dataset was established with 2,886 randomly photographed faces from visitors in a constructed urban forest park and a promenade at summertime in Shenyang City at Northeast China. Six experts were invited to choose 160 photos in total with 20 images representing one of eight typical expressions as angry, contempt, disgusted, happy, neutral, sad, scared, and surprised emotions. The FireFACE ver. 3.0 software was used to test hit-ratio validation as the accuracy (ac.) to match machine-recognized photos with those identified by experts. According to Kruskal-Wallis test on the difference from averaged scores in 20 recently published papers, contempt (ac. $=0.40 \%, P=0.0038$ ) and scared (ac. $=25.23 \%, P=0.0018)$ expressions cannot pass the validation test. Therefore, the FireFACE can be used as an instrument to analyze facial expression from oriental people in urban forests but contempt and scared expressions cannot be identified.
\end{abstract}

Keywords: urban greenspace; sustainable city; urban forest management; psychological well-being; mental health; stress relief

\section{Introduction}

The vital purpose to plant, grow, and manage urban tree populations is to enhance the ecological service of urban forests and also promote human well-being in urban green spaces [1]. The construction of sustainable urban forests needs to follow the principle that a community should promote the social and ecologic needs of people. Scientific evidence demonstrates that an urban forest experience can elicit emotional response which can be positive compared to that in a promenade $[2,3]$. The efficiency, however, may not always follow expected level to promote mental health $[4,5]$. The sustainability of constructed urban forests depends on the elaborate and scientific assessment on people's mental wellbeing.

Emotion is a transitory mental response to external stimuli [6]. The emotional response to a forest experience can be assessed by the questionnaire methodology [7]. Pilot studies in this context mainly argued that the forest experience can counter negative emotions through alleviating anxiety and stress [8-10]. However, a critical and vital issue in these studies is a systematic validation is lacking on the questionnaires with testing forest visitors [11]. In other words, despite that some self-rated scores revealed the emotional response to a forest experience, it is uncertain whether this response was related to internal emotions and to what extent were emotions matched by scores. 
Emotions can be represented through an assembly of facial expressions as either a felt expression with an emotional cue (Duchenne) or an unfelt expression with a communicative cue (non-Duchenne) [12]. Both kinds of facial expressions can be assessed through the instrument of facial expression recognizing technique [6]. Manual recognition of facial expressions developed a reliable method to evaluate emotions over five decades [13]. Recent studies are more reliable with automatic facial expression recognition instrument [14,15]. Using facial expression recognition software, differentiation of geography has been shown to be an effective stimulus that cues upon faces to show varied expressions with changed emotions [16,17]. The perception to infrastructure and openness are determinants of the emotional variation at different places $[17,18]$. When urban forests at different places were focused, people will also show spatial variation of emotional expressions that resulted from the perception to environmental factors $[19,20]$. Again, the validation of the instrument for facial expression recognition is lacking to the best of our knowledge.

The validation of face reading is a test of matching accuracy that can be quantified as a percentage agreement through artificial matching the aimed emotion $[13,21]$ or automatic machine reading $[14,15,22,23]$. Earlier methods to validate the accuracy of recognizing emotional expressions was assessed by the matching scores that were rated by observers towards photos with intended expressions [13]. This was easily termed as "the percentage of observers who choose the predicted label" [24]. This method was further developed by automatic recognition by instruments of software trained by datasets of expressions. Currently, the mostly common software for facial recognition includes Facial Action Coding System (FACS) [14,22], FaceReader [14,22], Affectiva Media Analytics (AFFDEX) iMotion [23], Face Analysis Computer Expression Toolbox (FACET), and iMotion [15,23]. Datasets of facial expressions that are frequently used to train machine learning for the software are mainly derived from the Warsaw Set of Emotional Facial Expression Pictures (WSEFEP) and Amsterdam Dynamic Facial Expression Set (ADFES) [22]. Therefore, the basic coding of the movement of facial muscles originated from prototypical expressions from western faces. However, facial expressions of emotion are not culturally universal [25], the detection of expressions on oriental faces would obtain a higher accuracy using the software that is trained by dataset all from eastern races. The validation of this difference by software should be more precise to employ the emotions that are predicted by oriental experts with clearly basic perception of the relationship between emotions and corresponding expressions.

FireFACE (Zhilunpudao Agric. S\&T Inc., Changchun, China) is a software that was produced to analyze expressions on faces of people of China [18]. The basic recognition of this software was established by machine training using a dataset with about 30,000 photos of facial expressions from oriental people. The production of version (ver.) 1.0 was trained by the document of three predicted expressions (happy, sad, and neutral) that were classified by experts, and the ver. 2.0 five expressions (happy, sad, neutral, angry, and scared). The ver. 3.0 was designed to analyze eight basic expressions (happy, sad, neutral, angry, scared, surprised, disgusted, and contempt) based on the initial dataset and the subsequently training with a dataset of photos about urban forest visitors with an oriental face which were continuously collected in urban forest parks across mainland China. Up to now, FireFACE ver. 1.0 has been successfully used for assessing the variation of emotional expressions in university campuses [18] and an urban forest park [20]. FireFACE ver. 3.0 has been used to detect the combined effects of geographical variation across urbanization gradient on facial expressions of urban forests in Northeast China [19]. Therefore, FireFACE has the desired precision in facial analysis for people in urban forests although mostly they tended to show subtle expressions. It is necessary to validate the matching accuracy of FireFACE ver. 3.0 to identify the availability of this software and to make basis for precise assessment of emotional expressions in constructed forests.

In this study, FireFACE ver. 3.0 was used to test its validation as analyzing expressions on oriental faces. A constructed urban forest park was investigated for its visitors to photograph their faces that were subsequently documented in a new dataset. An adjacent promenade was chosen as the place for the reference where the same time photos were taken on random pedestrians. Photos were randomly chosen from the dataset and eight prototypical expressions were classified by experts in urban studies for the test of validation. Based on current success of subtle expressions analysis 
using FireFACE, we hypothesized that FireFACE can pass the test of validation but with parts of expressions as the expected accuracy.

\section{Materials and Methods}

\subsection{Field Data Collection}

Field data were collected from an urban forest park and an adjacent promenade in Shenyang City $\left(41^{\circ} 11^{\prime}-42^{\circ} 17^{\prime} \mathrm{N}, 122^{\circ} 21^{\prime}-123^{\circ} 48^{\prime} \mathrm{E}\right)$. Shenyang is located in the transitional belt between Changbai Mountains and the alluvial plain of the Liaohe River. Shenyang is the capital City of Liaoning Province with 8.3 million permanent residents distributed in an area of 6.3 million $\mathrm{km}^{2}$ builtup region as of 2018. Shenyang is located in a zone of semihumid temperate continental climate with annual average temperature of $6.2-9.7{ }^{\circ} \mathrm{C}$ in a range of $-32.9^{\circ} \mathrm{C}$ and $38.4^{\circ} \mathrm{C}$. Annual rainfall in Shenyang ranged between 600 and $800 \mathrm{~mm}$ with historical maximum precipitation of $716.2 \mathrm{~mm}$ in built-up zone. Yearly frost-free periods lasted for 155-180 d. All these climatic data were cited from the document from 1951 to 2018 [26].

Shenyang Expo Garden (SEG) $\left(41^{\circ} 49^{\prime} \mathrm{N}, 123^{\circ} 37^{\prime} \mathrm{E}\right)$ was chosen as the site of urban forests and Shenyang Middle Street (SMS) $\left(41^{\circ} 48^{\prime} \mathrm{N}, 123^{\circ} 25^{\prime} \mathrm{E}\right)$ as the promenade (Figure 1). SEG was established in February of 1959 with an openness area of 211 ha with 196 ha of green lands and 6.5 ha of watershed. Urban forests in SEG were constructed since 1988. Daily population of visitors in SEG ranged between 0.3 million and 0.7 million which is the highest record for all green spaces around plain of the Liaohe River. SMS has a length of $579.3 \mathrm{~m}$ and a width of $11.7 \mathrm{~m}$, which is the longest promenade in mainland China. SMS has a long history of use from 1625 up to now. SMS is rarely greened along the sidewalk except which is fully occupied by groceries, markets, and plazas, which together attracts 0.4 to 2 million daily visitors. Therefore, SEG and SMS are two typical infrastructures with contrasting green spaces and constructed landscapes.

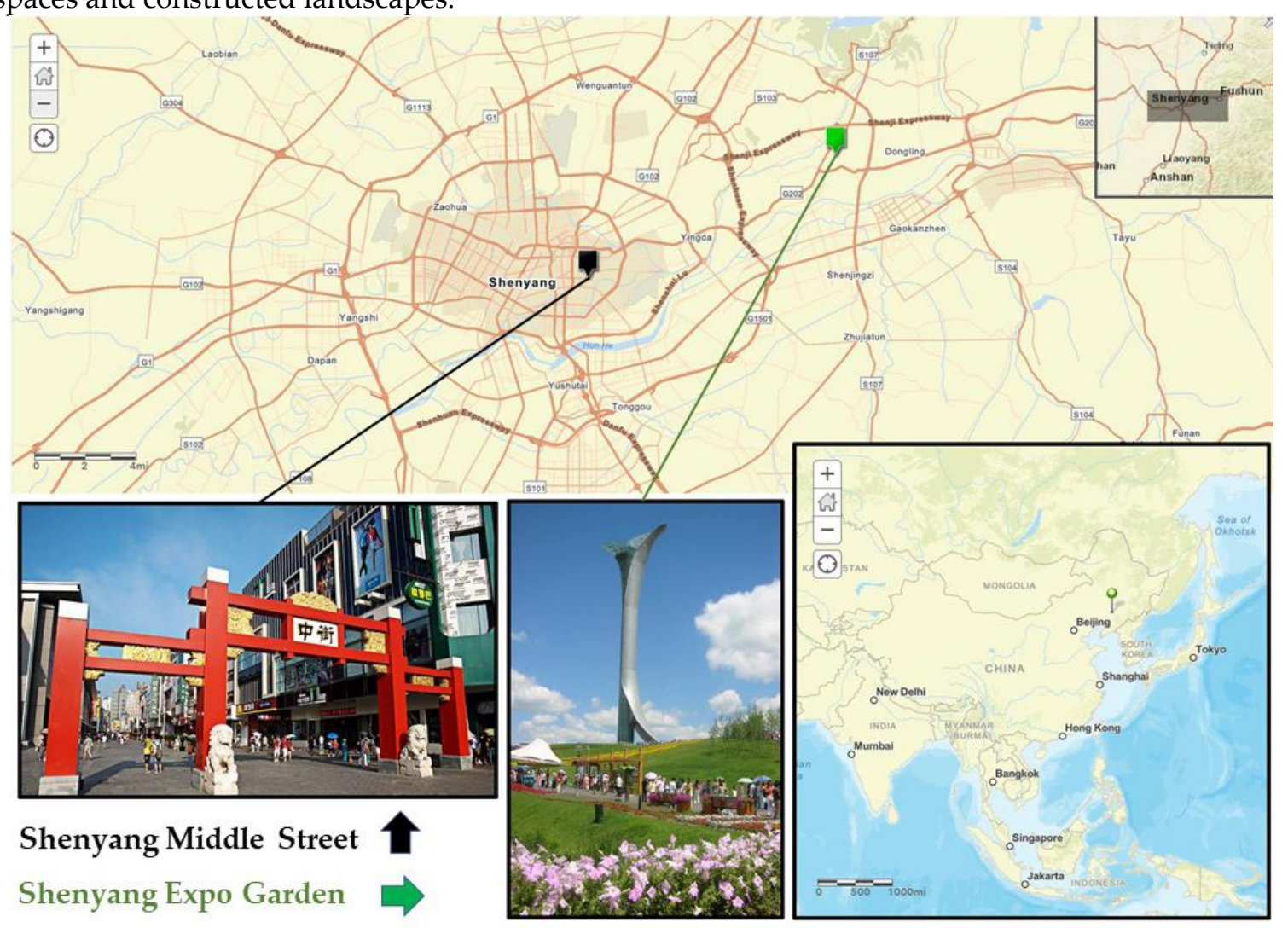

Figure 1. Geographical distribution of Shenyang Expo Garden (forest) and Shenyang Middle Street (Promenade or Urban) in Shenyang City, Northeast China. 


\subsection{Participants}

Eight students from College of Forestry, Shenyang Agricultural University were recruited as data collectors in this study. They were assembled with a group of volunteers on 19 June, 2020, when all were informed about the aim, process, and possible obstacles of the study. Only those who were aware and agreed to all the details about the study were recruited, those were had the habit of smoking or alcohol use were excluded in the recruitment. Eight students were randomly arranged to groups with four in one group. One group investigated one site with the other group in the other site on the first day, and in the next day places were exchanged. Within the group, two students took photos and the other two asked participants for the consent of using photos for scientific work. All photographers used a camera of imx-586 (Sony NEC Optiarc Inc., Tokyo, Japan) with 4 million px which was embedded in the cellphone.

On weekends of 20 and 21 June, 2020, all visitors in SEG and SMS were photographed with clear faces. Both days were sunny and cloudless except for the noon of 21 June from 12:00 to 14:00. The temperature ranged between $21^{\circ} \mathrm{C}$ and $32{ }^{\circ} \mathrm{C}$ in daytime with southwesterly winds at the velocity of Beaufort force $4(24 \mathrm{~km} / \mathrm{h}$ average speed). Photos in both sites were taken from 09:00 am to 05:00 pm $(\mathrm{GMT}+8)$ in accordance with the open time of SEG. The route in SEG started at the entrance and ended in the exit with 4 repeated cycles of data collection along the sidewalks, while that in SMS started at the northern entrance along the western side of sidewalk in the morning and the eastern side in the afternoon to avoid building shadows.

Ethical review committee: The Ethic Committee of the research group of Urban Forest and Wetland, Northeast Institute of Geography and Agroecology, Chinese Academy of Sciences (approval number: UFW-EC-2020-001).

\subsection{Available Photos with Facial Expressions}

All photos that fulfilled the standard for further analysis needed to connect at least one visitor's face with five facial organs of eyebrows, eyes, nose, mouse, and ears no matter to what angle of objects' faces towards the camera. Photos with only one ear but all the rest of facial organs were potential candidate images. All photos were cropped into smaller ones with only object's face in the center and all organs clearly exposed. A photo with a single object is the best candidate for facial analysis but that with several faces can also be employed when every face with aimed attributes was cropped and saved as a new photo file (Figure 2). Finally, a total of 2,886 photos were documented with available attributes for further analysis.

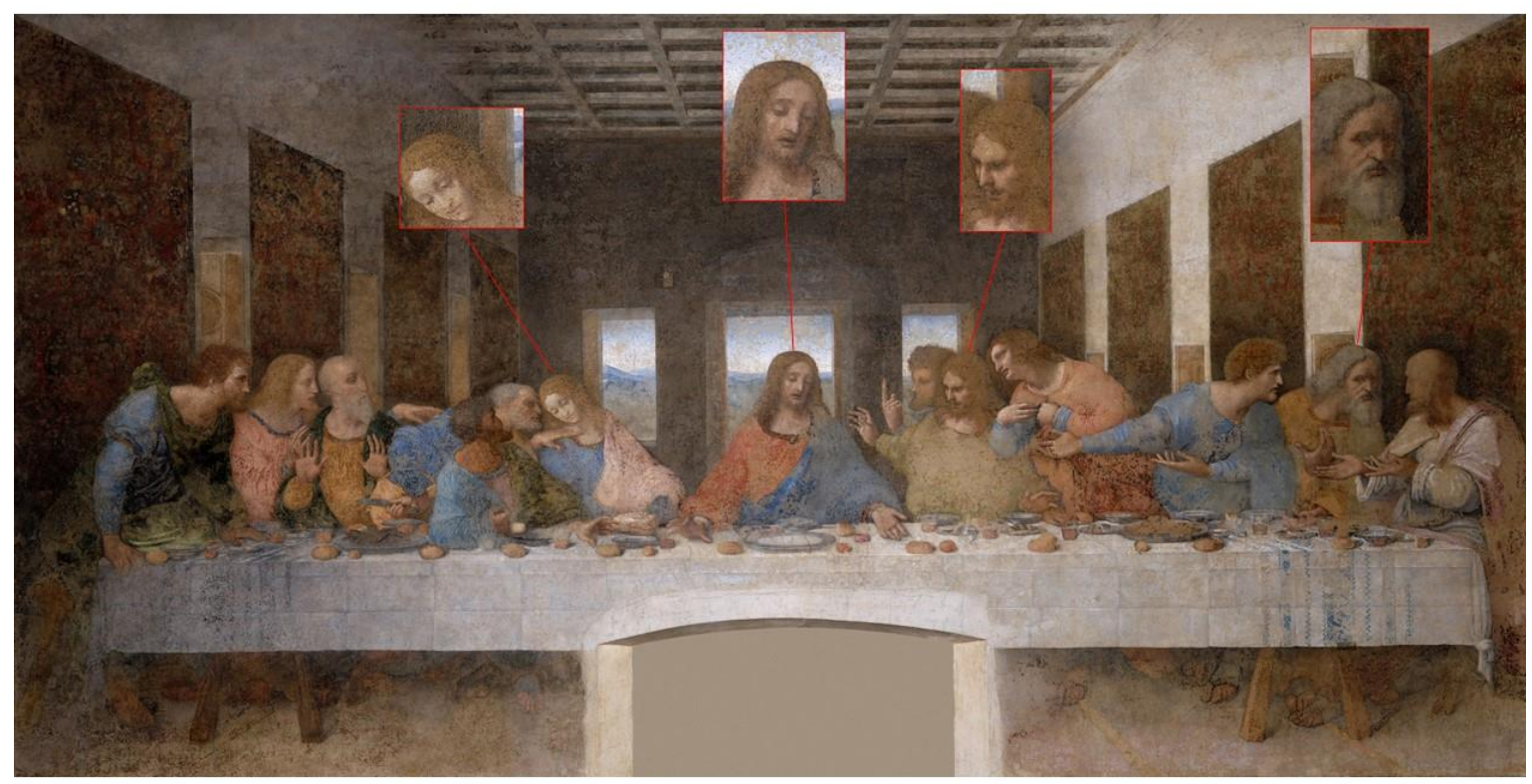


Figure 2. The typical approach to extract single portraits that meet the technical requirement for recognizing facial expressions from a group photo. The painting of The Last Supper is used as an instance of the group photo that is adapted from Wikipedia [27].

\subsection{Validation of Matching Accuracy}

A dataset of facial photos was generated from all documented photos for the validation. A total of 20 photos were selected from the pool of both SEG and SMS to show each angry, contempt, disgusted, happy, neutral, sad, scared, and surprised emotions. This created a total of 160 photos for to be reviewed by six experts in the domain of urban ecology from four affiliations. The final edition of the dataset was revised according to suggestions of all experts and obtained the agreement from all of them.

The validation was made with the detection of the variable of 'matching accuracy', which is the matching percentage of the number of photos that were correctly recognized by instrument for the most prototypical expression for each of the 20 images with the predicted emotional expressions [2830]. Therefore, the validation of matching accuracy can be regarded as the percent value for correct matching. It is possible every facial photo may contain all expressions in different emerging values, only the expression with highest value was taken as an unit to match the predicted one [23].

Give that the matching accuracy of validation for facial expressions varied in a wide range depending on the choice of database, methodology, and instrument, we established a set of standards to screen for the validation of each of the eight expressions in our photos from SEG or SMS. A combination of keywords of 'validation' + 'accuracy' + 'facial expression' was checked in the searching engine of Web of Science (Clarivate Analytics, Philadelphia, Pennsylvania, USA). The top 20 relevant studies with specific source of data (eight from figure, words, or tables) were documented for data extraction. The standard for employment screening was adapted as the mean of 20 studies (Table 1) [14,28-46]. The specific process of this part of study is shown in Figure 3. Only expressions that passed the standard were taken in the further assessment with those in failure abandoned from the study.

Table 1. Summary of matching accuracy for validation studies on facial expressions.

\begin{tabular}{|c|c|c|c|c|c|c|c|c|c|c|}
\hline \multirow{2}{*}{ Source } & \multirow{2}{*}{ Instrument } & \multirow{2}{*}{$\begin{array}{l}\text { Data } \\
\text { source }\end{array}$} & \multicolumn{8}{|c|}{ Matching accuracy (\%) } \\
\hline & & & Ang. ${ }^{1}$ & Con. $^{2}$ & Dis. $^{3}$ & Hap. $^{4}$ & Neu. ${ }^{5}$ & Sad & Sca. ${ }^{6}$ & Sur. ${ }^{7}$ \\
\hline $\begin{array}{l}\text { Banziger et al. } \\
\text { [31] }\end{array}$ & $\begin{array}{l}\text { Artificial } \\
\text { recognition }\end{array}$ & Figure & 27 & - & 85 & 56 & - & 47 & - & - \\
\hline $\begin{array}{l}\text { Ebner et al. } \\
{[33]}\end{array}$ & $\begin{array}{l}\text { Artificial } \\
\text { recognition }\end{array}$ & Figure & 80 & - & 69 & - & 84 & 73 & 84 & - \\
\hline $\begin{array}{l}\text { Besel and } \\
\text { Yuille [32] }\end{array}$ & $\begin{array}{l}\text { Artificial } \\
\text { recognition }\end{array}$ & Table & 82 & - & 55 & 69 & 75 & 58 & 54 & 51 \\
\hline $\begin{array}{l}\text { Matuszewski } \\
\text { et al. [35] }\end{array}$ & $\begin{array}{l}\text { Eigenface, } \\
\text { Fisherface }\end{array}$ & Table & 62 & - & 55 & 83 & - & 51 & 35 & 62 \\
\hline $\begin{array}{l}\text { Huang et al. } \\
\text { [34] }\end{array}$ & E-Prime & Figure & 54 & - & 32 & 63 & 43 & 33 & 27 & 21 \\
\hline $\begin{array}{l}\text { Maniglio et al. } \\
\text { [36] }\end{array}$ & $\begin{array}{l}\text { Artificial } \\
\text { recognition }\end{array}$ & Table & 50 & - & - & 93 & 65 & 75 & 65 & - \\
\hline $\begin{array}{l}\text { Zhang et al. } \\
\text { [38] }\end{array}$ & $\begin{array}{l}\text { Artificial } \\
\text { recognition }\end{array}$ & Table & 43 & - & - & 69 & - & 43 & - & - \\
\hline
\end{tabular}




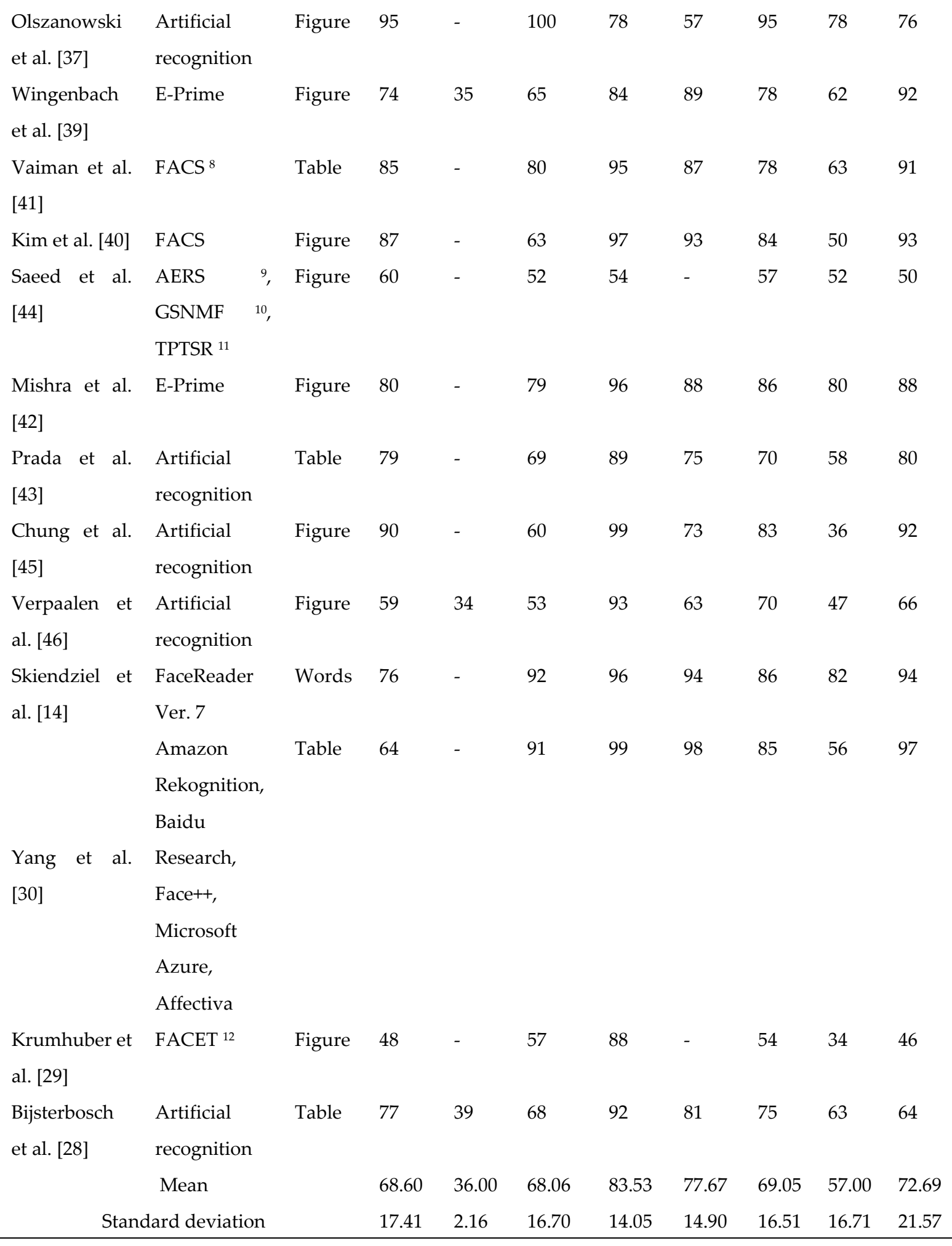

Note: ${ }^{1}$ Ang., angry; ${ }^{2}$ Con., contempt; ${ }^{3}$ Dis., disgusted; ${ }^{4}$ Hap., happy; ${ }^{5}$ Neu., neutral; 6 Sca., scared; 7 Sur., surprised; ${ }^{8}$ FACS, facial action coding system; 9 AERS, automatic expression recognition system; ${ }^{10}$ GSNMF, graph-preserving sparse nonnegative matrix factorization; ${ }^{11}$ TPTSR, two-phase test sample representation; ${ }^{12}$ FACET, iMotions Emotient toolbox. 


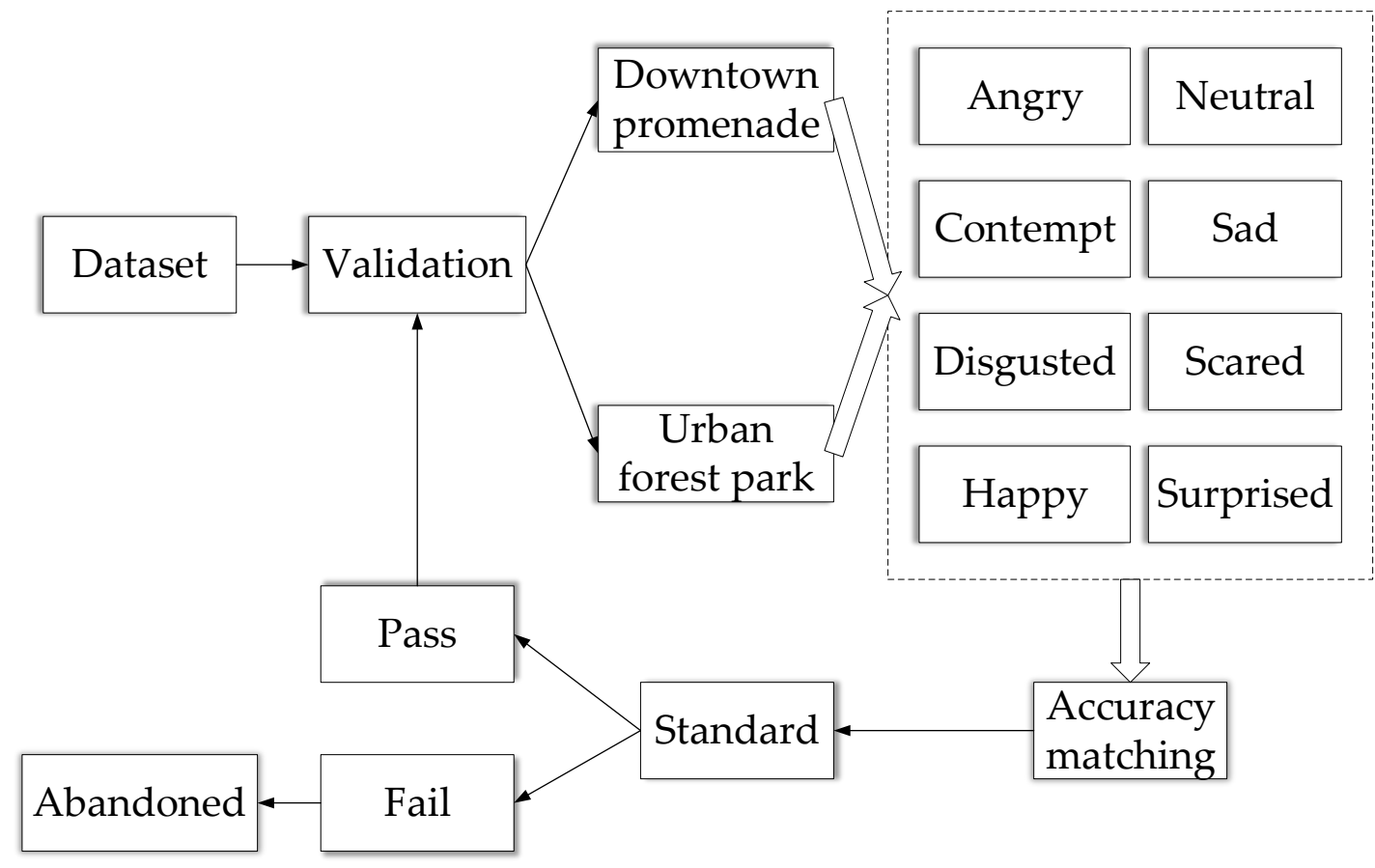

Figure 3. The whole process of the layout of whole study from validation to analysis.

\section{Results}

As it is shown in Table 1, the recent 20 publications that presented results about facial expression accuracy did not supply data for all eight expressions. For example, only three out of the 20 publications exposed accuracy for contempt expression and 15 for neutral expression. The highest accuracy was given for happy expression scores, followed by neutral and surprised expressions. The lowest accuracy was found when recognizing the contempt expression, and the rest were all over $50 \%$.

Results about the accuracies of recognizing eight facial expressions by the instrument of FireFACE are shown in Table 2. The accuracies for recognizing contempt and scared expressions were significantly lower than those from the average of 20 publications. Although averaged accuracy for the rest of facial expressions was lower by 18-69 \% in our database than that for historical ones, repeated Kruskal-Wallis tests did not indicate any significant difference because raw data showed a large variation in both our and previous databases. Therefore, we accept the accuracy to recognize facial expressions using the instrument of FireFACE software but only for the six expressions of anger, disgust, happiness, sadness, neutral, and surprise instead of the eight basic ones.

Table 2. Accuracy of eight facial expressions using FireFACE software and repeated Kruskal-Wallis tests on the difference from records in documented studies that are shown in Table 1.

\begin{tabular}{llllll}
\hline Facial expressions & DF & Accuracy $(\%)$ & SD $^{1}$ & Chi-Square & Pr $>$ Chi-Square ${ }^{2}$ \\
\hline Angry & 1 & 56.11 & 13.81 & 5.5388 & 0.0186 \\
Contempt & 1 & 0.40 & 0.90 & 8.3623 & $0.0038^{*}$ \\
Disgusted & 1 & 43.98 & 22.72 & 6.0610 & 0.0138 \\
Happy & 1 & 60.55 & 35.24 & 1.0296 & 0.3102 \\
Neutral & 1 & 23.85 & 20.89 & 7.3023 & 0.0069 \\
Sad & 1 & 55.53 & 11.69 & 7.1742 & 0.0074 \\
Scared & 1 & 25.23 & 20.57 & 9.6959 & $0.0018^{*}$ \\
Surprised & 1 & 47.57 & 15.75 & 2.8156 & 0.0934 \\
\hline
\end{tabular}

Note: ${ }^{1}$ SD, standard deviation; ${ }^{2}$ asterisk indicates significant difference at the 0.00625 level. 


\section{Discussion}

In our study, contempt and scared expression scores that were given by FireFACE software fail to pass the validation test. The scared expression was also hard to be recognized at an expected accuracy for faces of Chinese people even employing the three-dimensional paradigm technique [34]. The contempt emotion is a special feeling that can be hardly depicted by facial expressions not only by FireFACE software but also by other instruments with a wider range of users. This was also fully demonstrated by only three out of the recent 20 relevant publications had showed their accuracies of recognizing the contempt expression. The matching accuracy in these three cases were around 30\%, which was much lower than the simultaneous recognition of other expressions. In addition, two cases of accuracies were achieved by artificial rating $[28,46]$, and only one case published the matching accuracy given by an instrument of E-Prime [39]. Therefore, further improvement is needed of contempt expression for use by FireFACE because the scores were too low for accurate determination. The technique of machine learning needs to accelerate the understanding and recognizing the exhibition of contempt emotion in different groups of people.

Chinese people have typical oriental emotions that are exhibited with subjective-will in an implicit way rather than in the open way. The fear expressions on faces of Chinese people even reacted more slowly than other negative expressions when depicting pain even after the sad emotion priming [47]. The self-reserved habit to show scared expressions can also be extended to the Yonsei database from a Korean population [45]. Human and machine (FACET software) validations were compared across 14 datasets of dynamic facial expressions and only obtained a 34\% accuracy of recognizing a scared expression [29]. They further found that the scared expression was easily confused with surprised expression. Matuszewski et al. [35] checked the dataset of facial expressions from 80 clinic patients and, again, found the low recognizing rate of scared expression and agreed to the confusion with surprise. Matuszewski et al. [35] further compared different levels of scare scores and indicated that only when exposed to extreme pain would patients directly show fears on their faces or they would choose to reserve their expressions to avoid the perception by others. Overall, it is suggested to enhance the recognizing accuracy by more precisely distinguishing scare and surprise.

Our matching accuracy was generally lower than those found in previous studies. This can be explained by two aspects. The first was that our dataset that was used to train FireFACE contains subjective errors when artificially documenting different facial photos into any of the eight types of expressions. The second was that our objects receiving tests were collected from random photographing on visitors and subjectively documented with the label of typical facial expressions, hence the precision of expression exhibition was limited in addition to subjective error. In contrast, both machine-training and objects-testing in 20 existing studies reviewed in this paper employed model posers with instructions to exhibit aimed expressions. Even so, our results about the matching accuracies for six facial expressions of anger, disgust, happiness, sadness, neutral, and surprise were not statistically different from current ones. Therefore, the recognition by FireFACE is available for oriental faces with an acceptable accuracy for six expressions. Thus, we can accept our hypothesis.

\section{Conclusions}

We compared the accuracies to match the recognized facial expressions given by the FireFACE software with those assessed by other instruments or artificial approach. Facial expressions of angry, disgusted, happy, sad, neutral, and surprised emotions passed the validation test because their scores were within a level of statistical acceptance. However, contempt and scared expression scores were too low to make the difference fall in the significant range, and these were excluded from further analysis.

Funding: This research was funded by National Natural Science Foundation of China (grant numbers 41971122, and 41861017) and the Scholarship of Chinese Academy of Sciences for Overseas Study.

Acknowledgments: Authors acknowledge Prof. Yutao Wang from Shenyang Agricultural University, Prof. Shenglei Guo from Heilongjiang University of Chinese Medicine, and Dr. Qiao Li from Changchun Institute of 
Technology for their participation to review and revise the dataset for the validation of matching accuracy in addition to the effort from those in author board.

Conflicts of Interest: The author declares no conflict of interest.

\section{References}

1. Foo, C.H., Linking forest naturalness and human wellbeing-a study on public's experiential connection to remnant forests within a highly urbanized region in malaysia. Urban For. Urban Green. 2016, 16, 13-24.

2. Sonti, N.F., Ambivalence in the woods: Baltimore resident perceptions of local forest patches. Soc Natur Resour 2020, 33, 823-841.

3. Joung, D.; Kim, G.; Choi, Y.; Lim, H.; Park, S.; Woo, J.M.; Park, B.J., The prefrontal cortex activity and psychological effects of viewing forest landscapes in autumn season. Int. J. Env. Res. Pub. Health. 2015, 12, 7235-7243.

4. Akpinar, A.; Barbosa-Leiker, C.; Brooks, K.R., Does green space matter? Exploring relationships between green space type and health indicators. Urban For. Urban Green. 2016, 20, 407-418.

5. Wolf, K.L.; Lam, S.T.; McKeen, J.K.; Richardson, G.R.A.; van den Bosch, M.; Bardekjian, A.C., Urban trees and human health: A scoping review. Int. J. Env. Res. Pub. Health. 2020, 17, 30.

6. Ekman, P., Facial expression and emotion. Am. Psychol. 1993, 48, 384-392.

7. Takayama, N.; Saito, H.; Fujiwara, A.; Horiuchi, M., The effect of slight thinning of managed coniferous forest on landscape appreciation and psychological restoration. Prog. Earth Planet. Sci. 2017, 4, 15.

8. Bielinis, E.; Takayama, N.; Boiko, S.; Omelan, A.; Bielinis, L., The effect of winter forest bathing on psychological relaxation of young polish adults. Urban For. Urban Green. 2018, 29, 276-283.

9. Badiu, D.L.; Ioja, C.I.; Patroescu, M.; Breuste, J.; Artmann, M.; Nita, M.R.; Gradinaru, S.R.; Hossu, C.A.; Onose, D.A., Is urban green space per capita a valuable target to achieve cities' sustainability goals? Romania as a case study. Ecol. Indic. 2016, 70, 53-66.

10. Hauru, K.; Lehvavirta, S.; Korpela, K.; Kotze, D.J., Closure of view to the urban matrix has positive effects on perceived restorativeness in urban forests in helsinki, finland. Landscape Urban Plan. 2012, 107, 361-369.

11. Aerts, R.; Honnay, O.; Van Nieuwenhuyse, A., Biodiversity and human health: Mechanisms and evidence of the positive health effects of diversity in nature and green spaces. Brit. Med. Bull. 2018, 127, 5-22.

12. Surakka, V.; Hietanen, J.K., Facial and emotional reactions to duchenne and non-duchenne smiles. Int. J. Psychophysiol. 1998, 29, 23-33.

13. Ekman, P.; Sorenson, E.R.; Friesen, W.V., Pan-cultural elements in facial displays of emotion. Science 1969, 164, 86-88.

14. Skiendziel, T.; Rosch, A.G.; Schultheiss, O.C., Assessing the convergent validity between the automated emotion recognition software noldus facereader 7 and facial action coding system scoring. PLoS One 2019, $14,18$.

15. Calvo, M.G.; Fernandez-Martina, A.; Recio, G.; Lundqvist, D., Human observers and automated assessment of dynamic emotional facial expressions: Kdef-dyn database validation. Front. Psychol. 2018, 9, 12.

16. Ali, G.; Ali, A.; Ali, F.; Draz, U.; Majeed, F.; Yasin, S.; Ali, T.; Haider, N., Artificial neural network based ensemble approach for multicultural facial expressions analysis. Ieee Access 2020, 8, 134950-134963.

17. Kang, Y.H.; Jia, Q.Y.; Gao, S.; Zeng, X.H.; Wang, Y.Y.; Angsuesser, S.; Liu, Y.; Ye, X.Y.; Fei, T., Extracting human emotions at different places based on facial expressions and spatial clustering analysis. T. Gis 2019, $23,450-480$. 
18. Wei, H.X.; Hauer, R.J.; Zhai, X.Q., The relationship between the facial expression of people in university campus and host-city variables. Appl. Sci. 2020, 10, 17.

19. Wei, H.X.; Hauer, R.J.; Chen, X.; He, X.Y., Facial expressions of visitors in forests along the urbanization gradient: What can we learn from selfies on social networking services? Forests 2019, 10, 14.

20. Wei, H.X.; Ma, B.Q.; Hauer, R.J.; Liu, C.Y.; Chen, X.; He, X.Y., Relationship between environmental factors and facial expressions of visitors during the urban forest experience. Urban For. Urban Green. 2020, 53, 10.

21. Langner, O.; Dotsch, R.; Bijlstra, G.; Wigboldus, D.H.J.; Hawk, S.T.; van Knippenberg, A., Presentation and validation of the radboud faces database. Cogn. Emot. 2010, 24, 1377-1388.

22. Lewinski, P.; den Uyl, T.M.; Butler, C., Automated facial coding: Validation of basic emotions and facs aus in facereader. J Neurosci Psychol E 2014, 7, 227-236.

23. Stockli, S.; Schulte-Mecklenbeck, M.; Borer, S.; Samson, A.C., Facial expression analysis with affdex and facet: A validation study. Behav. Res. Methods 2018, 50, 1446-1460.

24. Nelson, N.L.; Russell, J.A., Universality revisited. Emotion Review 2013, 5, 8-15.

25. Jack, R.E.; Garrod, O.G.B.; Yu, H.; Caldara, R.; Schyns, P.G., Facial expressions of emotion are not culturally universal. PNAS 2012, 109, 7241-7244.

26. Baidu Cyclopedia Shenyang city (the capital of liaoning province, deputy provincial city) https://baike.baidu.com/item/\%E6\%B2\%88\%E9\%98\%B3/13034?fromtitle=\%E6\%B2\%88\%E9\%98\%B3\%E5\%B $\underline{8 \% 82 \& \text { fromid }=124784 \& \text { fr }=\text { aladdin }}$ (11 June),

27. Wikipedia The last supper https://en.wikipedia.org/wiki/The_Last_Supper_(Leonardo)\#/media/File:The_Last_Supper_Leonardo Da Vinci - High Resolution 32x16.jpg (2 October),

28. Bijsterbosch, G.; Mobach, L.; Verpaalen, I.A.M.; Bijlstra, G.; Hudson, J.L.; Rinck, M.; Klein, A.M., Validation of the child models of the radboud faces database by children. Int. J. Behav. Dev. 2020, 7.

29. Krumhuber, E.G.; Kuster, D.; Namba, S.; Skora, L., Human and machine validation of 14 databases of dynamic facial expressions. Behav. Res. Methods 2020, 16.

30. Yang, K.N.; Wang, C.F.; Sarsenbayeva, Z.; Tag, B.; Dingler, T.; Wadley, G.; Goncalves, J., Benchmarking commercial emotion detection systems using realistic distortions of facial image datasets. Visual Comp. 2020, 20.

31. Banziger, T.; Grandjean, D.; Scherer, K.R., Emotion recognition from expressions in face, voice, and body: The multimodal emotion recognition test (mert). Emotion 2009, 9, 691-704.

32. Besel, L.D.S.; Yuille, J.C., Individual differences in empathy: The role of facial expression recognition. Pers. Indiv. Indiv. Differ. 2010, 49, 107-112.

33. Ebner, N.C.; Riediger, M.; Lindenberger, U., Faces-a database of facial expressions in young, middle-aged, and older women and men: Development and validation. Behav. Res. Methods 2010, 42, 351-362.

34. Huang, C.L.C.; Hsiao, S.; Hwu, H.G.; Howng, S.L., The chinese facial emotion recognition database (cferd): A computer-generated 3-d paradigm to measure the recognition of facial emotional expressions at different intensities. Psych. Res. 2012, 200, 928-932.

35. Matuszewski, B.J.; Quan, W.; Shark, L.K.; McLoughlin, A.S.; Lightbody, C.E.; Emsley, H.C.A.; Watkins, C.L., Hi4d-adsip 3-d dynamic facial articulation database. Image Vision Comput. 2012, 30, 713-727.

36. Maniglio, R.; Gusciglio, F.; Lofrese, V.; Murri, M.B.; Tamburello, A.; Innamorati, M., Biased processing of neutral facial expressions is associated with depressive symptoms and suicide ideation in individuals at risk for major depression due to affective temperaments. Compr. Psychiat. 2014, 55, 518-525. 
37. Olszanowski, M.; Pochwatko, G.; Kuklinski, K.; Scibor-Rylski, M.; Lewinski, P.; Ohme, R.K., Warsaw set of emotional facial expression pictures: A validation study of facial display photographs. Front. Psychol. 2015, 5,8 .

38. Zhang, F.; Parmley, M.; Wan, X.A.; Cavanagh, S., Cultural differences in recognition of subdued facial expressions of emotions. Motiv. Emotion 2015, 39, 309-319.

39. Wingenbach, T.S.H.; Ashwin, C.; Brosnan, M., Validation of the amsterdam dynamic facial expression set bath intensity variations (adfes-biv): A set of videos expressing low, intermediate, and high intensity emotions. PLoS One 2016, 11, 28.

40. Kim, S.M.; Kwon, Y.J.; Jung, S.Y.; Kim, M.J.; Cho, Y.S.; Kim, H.T.; Nam, K.C.; Kim, H.J.; Choi, K.H.; Choi, J.S., Development of the korean facial emotion stimuli: Korea university facial expression collection $2^{\text {nd }}$ edition. Front. Psychol. 2017, 8, 11.

41. Vaiman, M.; Wagner, M.A.; Caicedo, E.; Pereno, G.L., Development and validation of an argentine set of facial expressions of emotion. Cogn. Emot. 2017, 31, 249-260.

42. Mishra, M.V.; Ray, S.B.; Srinivasan, N., Cross-cultural emotion recognition and evaluation of radboud faces database with an indian sample. PLoS One 2018, 13, 19.

43. Prada, M.; Garrido, M.V.; Camilo, C.; Rodrigues, D.L., Subjective ratings and emotional recognition of children's facial expressions from the cafe set. PLoS One 2018, 13, 21.

44. Saeed, S.; Mahmood, M.K.; Khan, Y.D., An exposition of facial expression recognition techniques. Neural Comput. Appl. 2018, 29, 425-443.

45. Chung, K.M.; Kim, S.; Jung, W.H.; Kim, Y., Development and validation of the yonsei face database (yface db). Front. Psychol. 2019, 10, 18.

46. Verpaalen, I.A.M.; Bijsterbosch, G.; Mobach, L.; Bijlstra, G.; Rinck, M.; Klein, A.M., Validating the radboud faces database from a child's perspective. Cogn. Emot. 2019, 33, 1531-1547.

47. Song, J.; Wei, Y.Q.; Ke, H., The effect of emotional information from eyes on empathy for pain: A subliminal erp study. PLoS One 2019, 14, 15.

(C) 2020 by the authors. Submitted for possible open access publication under the terms and conditions of the Creative Commons Attribution (CC BY) license (http://creativecommons.org/licenses/by/4.0/). 